\title{
Induction of p21 WAF1/CIP1/SDI1 in Kidney Tubule Cells Affects the Course of Cisplatin-induced Acute Renal Failure
}

\author{
Judit Megyesi, ${ }^{\star}$ Robert L. Safirstein, ${ }^{\star}$ and Peter M. Price ${ }^{\star \ddagger}$ \\ Department of Medicine, *Division of Nephrology and ${ }^{\ddagger}$ Sealy Center for Molecular Science, University of Texas Medical Branch, \\ Galveston, Texas 77555
}

\begin{abstract}
The p21 protein is found in the nucleus of most cells at low levels and is induced to elevated levels after DNA damage, causing cell-cycle arrest. We have reported that p21 mRNA is rapidly induced to high levels in murine kidney after acute renal failure. The function(s) in the kidney of p21 induction in cisplatin-induced acute renal failure was studied with mice that are homozygous for a p21 gene deletion. After drug administration, as compared with their wild-type littermates, p21(-I-) mice display a more rapid onset of the physiologic signs of acute renal failure, develop more severe morphologic damage, and have a higher mortality. Therefore, the induction of p21 after cisplatin administration is a protective event for kidney cells. Using both bromodeoxyuridine incorporation and nuclear proliferating cell nuclear antigen detection, we found that cisplatin administration caused kidney cells to start entering the cellcycle. However, cell-cycle progression is inhibited in wildtype mice, whereas kidney cells in the $p 21(-I-)$ mice progress into S-phase. We propose that p21 protects kidneys damaged by cisplatin by preventing DNA-damaged cells from entering the cell-cycle, which would otherwise result in death from either apoptosis or necrosis. (J. Clin. Invest. 1998. 101:777-782.) Key words: cell cycle • apoptosis • necrosis • cyclin-dependent kinase $•$ DNA damage
\end{abstract}

\section{Introduction}

Experimental models of acute renal failure caused by ischemia, nephrotoxic drugs (e.g., cisplatin), and ureteral obstruction result in severe and acute reduction in the glomerular filtration rate, accompanied by increased serum concentrations of blood urea nitrogen (BUN). ${ }^{1}$ For ischemia and most nephrotoxic drugs, there is also morphologic damage of varying de-

Address correspondence to Peter M. Price, Ph.D., Associate Professor, Department of Internal Medicine, Division of Nephrology, University of Texas Medical Branch, Room 4.200 John Sealy, 301 University Blvd., Galveston, TX 77555-0562. Phone: 409-772-8244; FAX: 409-772-5451; E-mail: pprice@impo1.utmb.edu

Received for publication 13 August 1997 and accepted in revised form 8 December 1997.

1. Abbreviations used in this paper: BrdU, bromodeoxyuridine; BUN, blood urea nitrogen; cdk, cyclin-dependent kinase; PCNA, proliferating cell nuclear antigen.

J. Clin. Invest.

(C) The American Society for Clinical Investigation, Inc. 0021-9738/98/02/0777/06 \$2.00

Volume 101, Number 4, February 1998, 777-782

http://www.jci.org grees of necrosis, especially of the $\mathrm{S} 3$ segment of the proximal tubules. Previously, we had demonstrated a rapid and high level induction of a cell-cycle inhibitory protein, $\mathrm{p} 21$, in murine kidney after acute renal failure, including after cisplatin administration (1). p21, also known as WAF-1 (2), Cip-1 (3), and Sdi-1 (4), is a protein of $21 \mathrm{kD}(5)$ and a member of a protein family containing also $\mathrm{p} 27^{\mathrm{KIP} 1}(6)$ and $\mathrm{p} 57^{\mathrm{KIP} 2}(7,8)$. The $\mathrm{p} 21$ protein is constitutively expressed at low levels in most cells and is present in the nucleus as a member of a quaternary complex with cyclin, cyclin-dependent kinase (cdk), and proliferating cell nuclear antigen (PCNA) $(9,10)$. These low levels of p21 are thought to contribute to the stability of the cyclin-cdk association (11). The p21 protein has been shown to be overexpressed before terminal differentiation (12-18), and in cultured cells undergoing senescence (4). In addition, the $p 21$ gene is induced after DNA damage (2), and its induction is necessary for the p53-dependent cell-cycle arrest after DNA damage (19-21). Induction of the $p 21$ gene and overexpression of the $\mathrm{p} 21$ protein is associated with cell-cycle interruption and G1 arrest $(2,3,22-25)$, and p21 has been shown to inhibit one or more of the cyclin-cdk kinase activities $(3,22,25)$. The protein can also bind $(26)$ and inhibit $(27,28)$ PCNA, especially its role in DNA replication rather than DNA repair (29). The role of $\mathrm{p} 21$ in differentiation is probably redundant, since mice lacking p21 develop normally (27). Its role in cisplatin-induced acute renal failure is the subject of this investigation.

\section{Methods}

p21(-/-) mice (20) and induction of acute renal failure. Mice carrying a deletion of a large portion of the $p 21$ gene in which neither $\mathrm{p} 21$ mRNA nor p21 protein is expressed were obtained from Dr. Philip Leder (Harvard Medical School, Cambridge, MA). The mice homozygous for the $p 21$ deletion were selected from the offspring of heterozygous matings using Southern blotting of tail DNA as described (20). Similarly, wild-type homozygous littermates were selected as controls. Male mice from 8 to $15 \mathrm{wk}$ of age were studied as described. The animals used in these studies were housed at the Animal Research Center at the University of Texas Medical Branch at Galveston. When appropriate, animals were painlessly killed in accordance with methods of euthanasia approved by the Panel on Euthanasia of the American Veterinary Medical Association. Cisplatin was administered by a single intraperitoneal injection to mice at 20 $\mathrm{mg} / \mathrm{kg}$. The induction of acute renal failure was monitored by following BUN (Sigma No. 535; Sigma Chemical Co., St. Louis, MO) concentrations in serum obtained by retroorbital bleeding.

Morphologic assessment. At various times after cisplatin treatment, kidneys were removed, immersed in $4 \%$ neutral-buffered formaldehyde, and fixed for 48-72 h. After several washes with PBS and cryoprotection in $20 \%$ sucrose in PBS, the tissues were embedded in OCT and frozen in liquid nitrogen. Thin $(6-8 \mu \mathrm{m})$ sections were cut in a cryostat and placed onto slides coated with 3-aminopropyltriethoxysilane. The tissues were stained with hematoxylin and eosin and PAS, and the degree of morphological involvement in renal failure was determined using light microscopy. The following parameters were chosen as indicative of morphological damage to the kid- 
ney after cisplatin injection: brush border loss, red blood cell extravasation, tubule dilatation, tubule degeneration, tubule necrosis, and tubular cast formation. These parameters were evaluated on a scale of 0 to 4, which ranged from not present (0), mild (1), moderate (2), severe (3), to very severe (4). Each parameter was determined on at least five different animals. Statistical significance was assessed by the two-sided Student's $t$ test for independent samples, and was indicated in Figs. $1-3$ if the $P$ value was 0.05 or less.

Apoptosis detection (30) and quantification. The TUNEL technique (Apoptag kit; Oncor Inc., Gaithersburg, MD) was used to detect apoptotic cells in situ. All apoptotic nuclei within a section of kidney were counted and the results expressed as the number determined per square millimeter of kidney. Statistical significance was assessed as above.

Cell-cycle analysis. Incorporation and detection of bromodeoxyuridine (BrdU) into kidney nuclei was performed as described by Godley et al. (31) using a kit from Boehringer Mannheim (Indianapolis, IN). Nuclear PCNA was detected using a mouse monoclonal PCNA antibody (Santa Cruz Laboratory, Santa Cruz, CA) and the ABC Elite Vectastain Kit (Vector Laboratories, Inc., Burlingame, CA). Because of the large differences in both BrdU incorporation and PCNA staining between $p 21(-/-)$ and wild-type kidney sections after cisplatin injection, statistical analyses were not performed on these samples.

\section{Results}

Quantification of physiological measurements of kidney function. As shown in Fig. 1, the BUN values in untreated animals were nearly identical. $1 \mathrm{~d}$ after cisplatin injection, the values in the wild-type mice population were still within the untreated range. However, at this time, the values in the $p 21(-/-)$ population were severely elevated and were statistically different from the wild-type values $(P=0.020)$. After 2 and $3 \mathrm{~d}$ of cisplatin injection, the BUN of the wild-type mice was elevated, but never to the extent of the $p 21(-/-)$ mice. Also, between 2 and $3 \mathrm{~d}$, the $p 21(-/-)$ mice had a mortality rate of $\sim 30 \%$, whereas no mortality was observed in the wild-type mice (data not shown). Each time point represented the mean ( \pm standard error) from at least six mice.

Quantification of morphologic damage. The histologic examination of kidney tissue $1 \mathrm{~d}$ after cisplatin injection showed

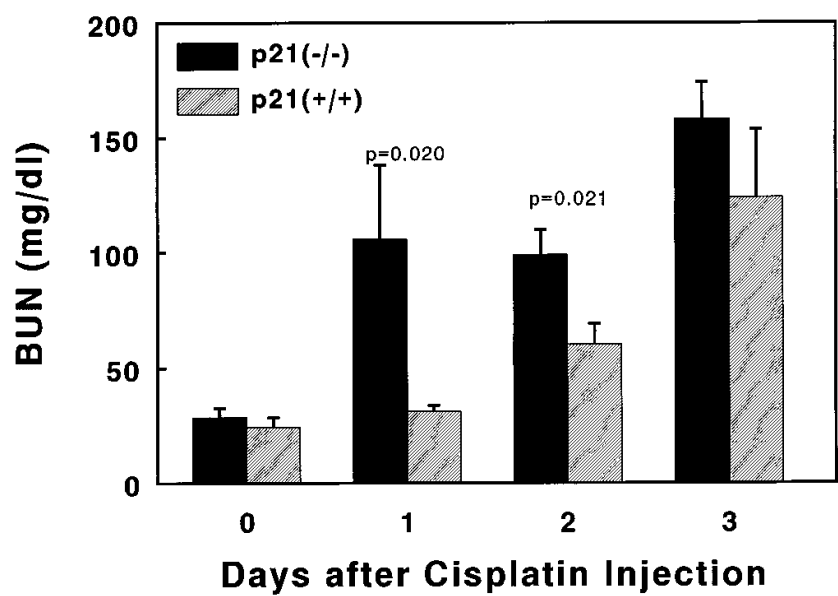

Figure 1. Urea nitrogen levels in serum (BUN) after cisplatin administration. Values, in milligrams per deciliter, at each time point represent means ( \pm standard error) of at least six mice. Statistically significant differences $(P<0.05)$ are indicated. that very few changes could be observed in the wild-type (Fig. $2 A$ ), whereas in the $p 21(-/-)$ mice (Fig. $2 B$ ), there was red blood cell extravasation, and proximal tubule damage from brush border loss, dilatation, and degeneration. This is quantified in Fig. 2 C. 3 d after injection, the wild-type mice (Fig. 2 $D$ ) exhibited red blood cell extravasation, and proximal tubule damage such as brush border loss, dilatation, degeneration, cast formation, and necrosis. Necrosis was restricted to the S3 segment. Not only did $p 21(-/-)$ mice (Fig. 2 E) exhibit much more severe damage in all categories, but the proximal tubule necrosis extended throughout $\mathrm{S} 1, \mathrm{~S} 2$, and $\mathrm{S} 3$ segments. This is quantified in Fig. $2 F$.

Apoptotic bodies were observed in the hematoxylin and eosin-stained kidney sections, especially in the $p 21(-/-)$ mice $3 \mathrm{~d}$ after cisplatin injection. However, a more exact quantification based on these observations was not possible primarily because of the amount of necrotic debris in these kidney sections and of the relatively short life span of an apoptotic body. Therefore, apoptosis was determined by the TUNEL technique (30). Using this method, we could detect very few stained nuclei in kidney sections prepared from untreated mice. Also, even in the presence of extensive necrosis, the necrotic debris was primarily unstained and easily distinguishable from apoptotic staining, which appeared only in nuclei. Sections from mice $3 \mathrm{~d}$ after cisplatin injection are shown in Fig. 3, $A$ and $B$, and a time course of appearance of apoptotic nuclei is quantified in Fig. $3 C$. In the $p 21(-/-)$ mice, statistically significant increases in apoptotic cells could be observed starting $1 \mathrm{~d}$ after cisplatin injection. In wild-type mice, apoptotic nuclei were only observed in cells of the distal nephron, especially in distal convoluted tubules and collecting ducts. In $p 21(-/-)$ mice, apoptotic cells occurred throughout the kidney, both in distal and proximal regions of the nephron, especially in both proximal and distal convoluted tubules and collecting ducts.

Cell-cycle analysis. Both BrdU incorporation (Fig. 4, A and $B$ ) into nuclear DNA and nuclear PCNA (Fig. 4, $C$ and $D$ ) were much higher in $p 21(-/-)$ mice. In both populations, before cisplatin injection, only minimal $\mathrm{BrdU}$ incorporation or PCNA could be detected (data not shown). The localization of both BrdU and PCNA positive cells was similar to that of the apoptotic cells. In the wild-type mice all of the positive cells were localized in the distal nephron, primarily the distal convoluted tubules and collecting ducts and in p21(-/-) mice, positive cells were in these distal nephron tubules and in proximal tubules. In addition, in $p 21(-/-)$ mice, positive cells were localized in the Bowman's capsule of the glomerulus.

\section{Discussion}

The molecular changes that occur in acute renal failure are likely to be underlying causes of many of the pathophysiological consequences of the syndrome as well as mechanisms for recovery. A thorough understanding of these molecular changes and their consequences would likely enable investigators to gain insight into the treatment and/or prevention of renal failure. In this regard, the known pathways of cellular responses to p21 overexpression make it a likely candidate to be intimately involved in certain aspects of acute renal failure. First, we have shown it to be highly overexpressed in kidney cells during both the injury and recovery phases of acute renal failure (1). Second, it is expressed in all types of acute renal failure so far investigated, including ischemia, ureteral obstruc- 

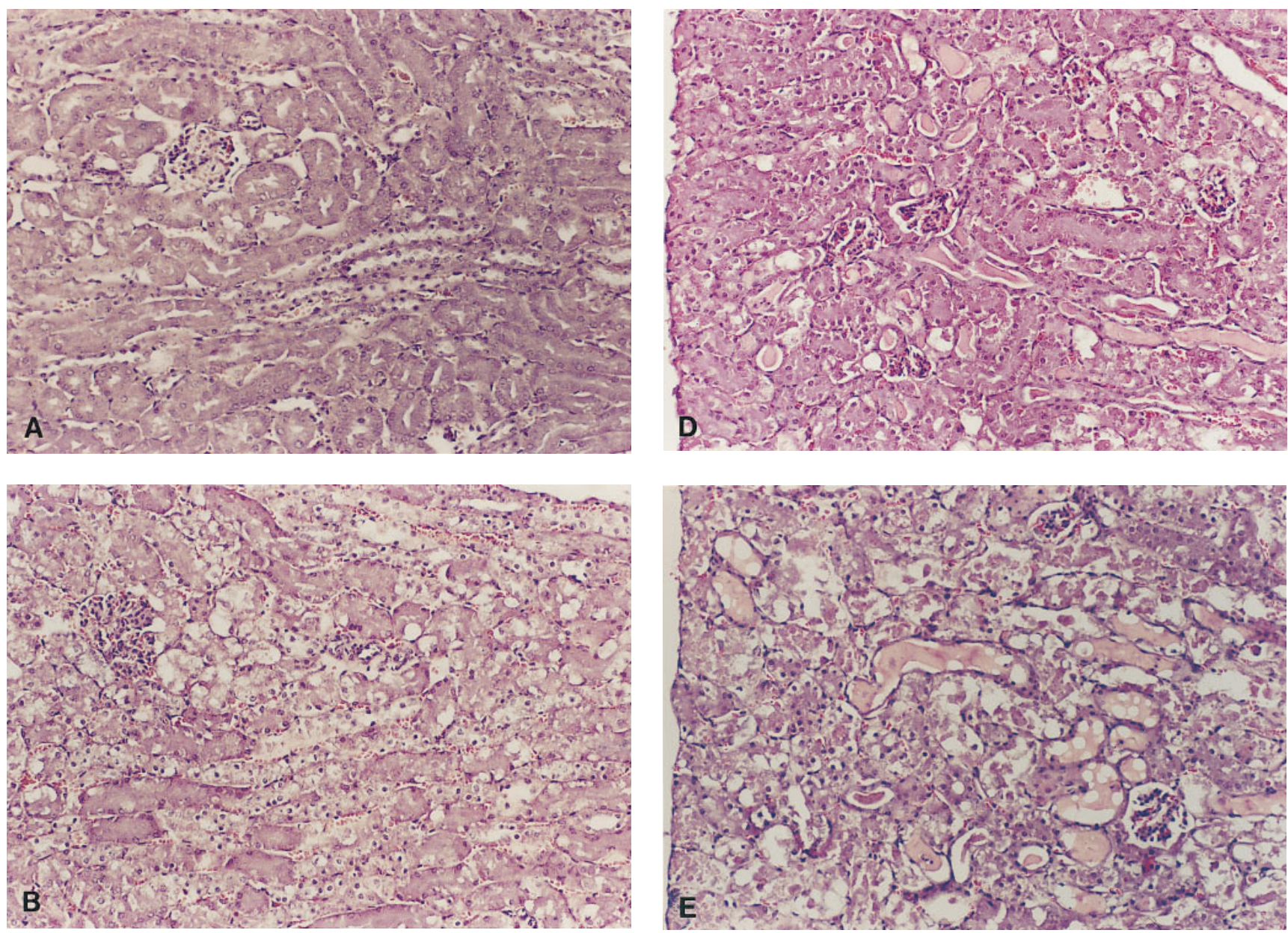

C

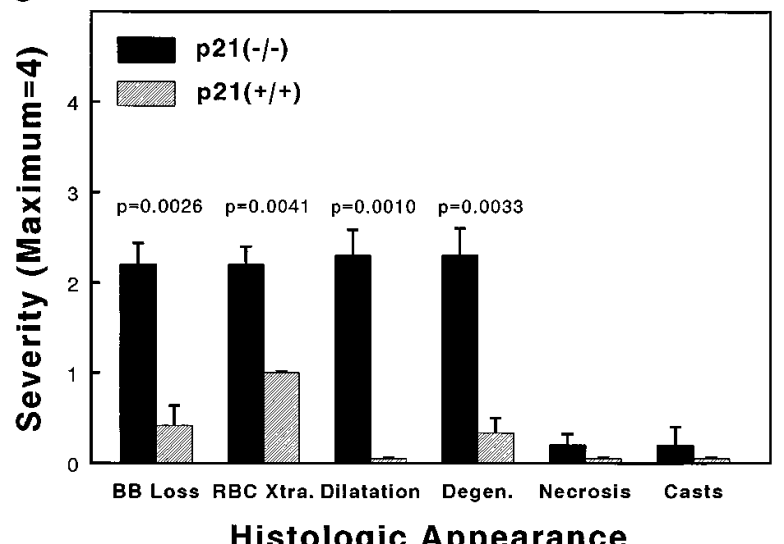

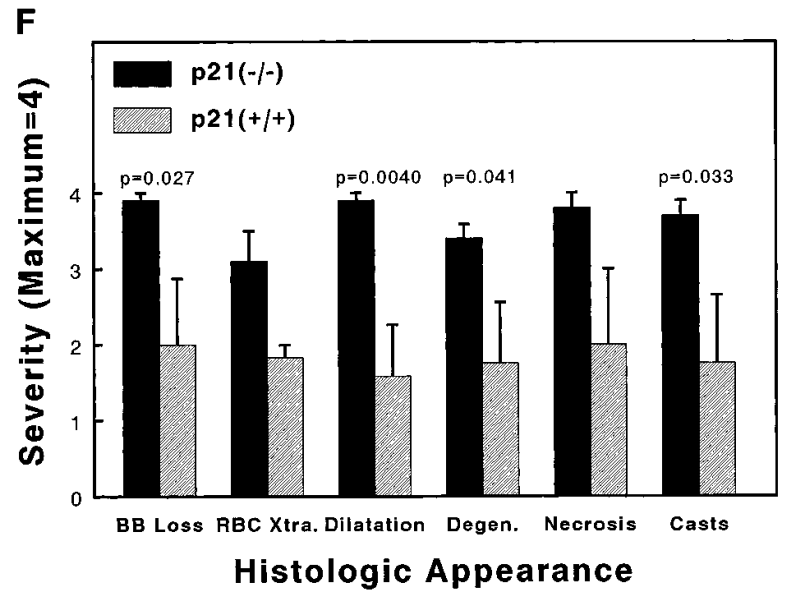

Figure 2. Histologic evaluation of kidney after cisplatin injection. Representative sections from either $1 \mathrm{~d}(A$ and $B)$ or $3 \mathrm{~d}(D$ and $E)$ after injection of wild-type $(A$ and $D)$ or $p 21(-/-)$ mice $(B$ and $E)$. $\times 390$. Quantitative evaluation of morphologic kidney damage $1 \mathrm{~d}(C)$ and $3 \mathrm{~d}(F)$ after injection of wild-type or $p 21(-/-)$ mice expressed as relative severity on a scale from 0 to 4 . Values represent means ( \pm standard error) of kidney sections from at least five mice for each time point and genotype. Morphology was scored according to proximal tubule brush border loss (BB Loss), red blood cell extravasation (RBC Xtra.), tubule dilation (Dilatation), tubule degeneration (Degen.), tubule necrosis (Necrosis), and cast formation within tubules $($ Casts $)$. Statistically significant differences $(P<0.05)$ are indicated.

tion, and nephrotoxic drug administration (1). Third, its overexpression is known to cause cell-cycle interruption, and the kidney cells in which it is expressed during ischemia do not undergo DNA synthesis or mitosis after injury even though these cells are the site of immediate-early gene induction (32). Finally, its induction in kidney after cisplatin injection is in part controlled by p53-dependent mechanisms that also participate in reparative functions after DNA damage. 

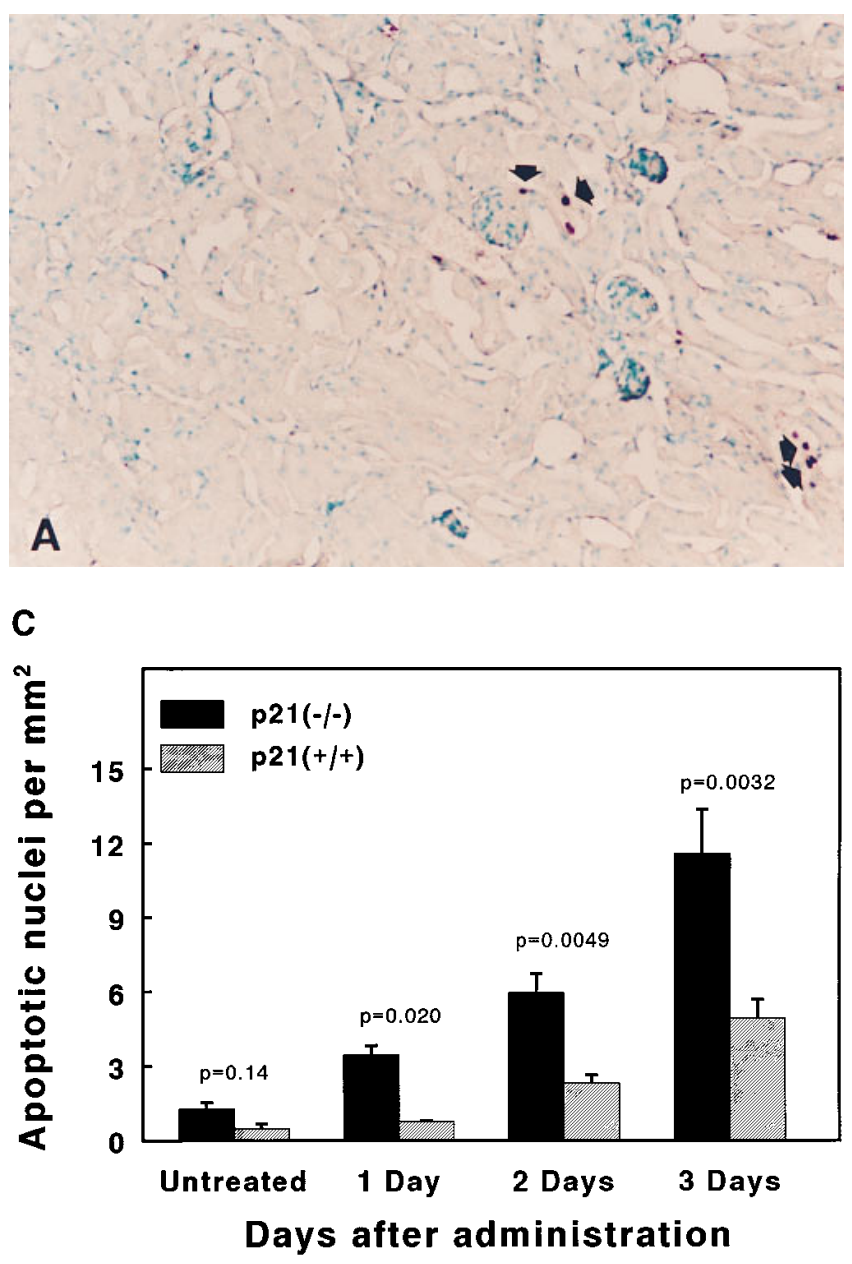

We have found, using the cisplatin model of acute renal failure, that both morphologic and physiologic injuries are more severe in mice lacking p21 than in their wild-type littermates, whereas in the absence of renal failure, kidney morphology and physiology are identical in the two populations. The urea nitrogen in serum $1 \mathrm{~d}$ after cisplatin administration still had near normal values in the wild-type population, while the values were severely elevated in the $p 21(-/-)$ mice (Fig. $1)$. These differences continued throughout the course of the measurements (3d). Measurements were not continued past this point because of the mortality $(\sim 30 \%)$ observed in the p21(-/-) population, which was not seen in the wild-type mice. Kidney histology after cisplatin administration was also severely affected by the lack of a functional $p 21$ gene. After $1 \mathrm{~d}$, we observed statistical differences in red blood cell extravasation, proximal tubule brush border loss, dilatation, and degeneration (Fig. $2 C$ ). After $3 \mathrm{~d}$, all measured histologic parameters were more severe in the $p 21(-/-)$ mice (Fig. $2 F$ ). At this point, proximal tubule necrosis, which in wild-type mice mainly involved the S3 segment, extended throughout all segments (S1, S2, S3). Similar differences in the number of apoptotic cells were observed between the $p 21(-/-)$ and wild-type populations (Fig. $3 \mathrm{C}$ ).

The induction of programmed cell death or apoptosis by tumor suppressor p53-dependent pathways is associated with the trans-activation of the p21 gene (23). However, it was

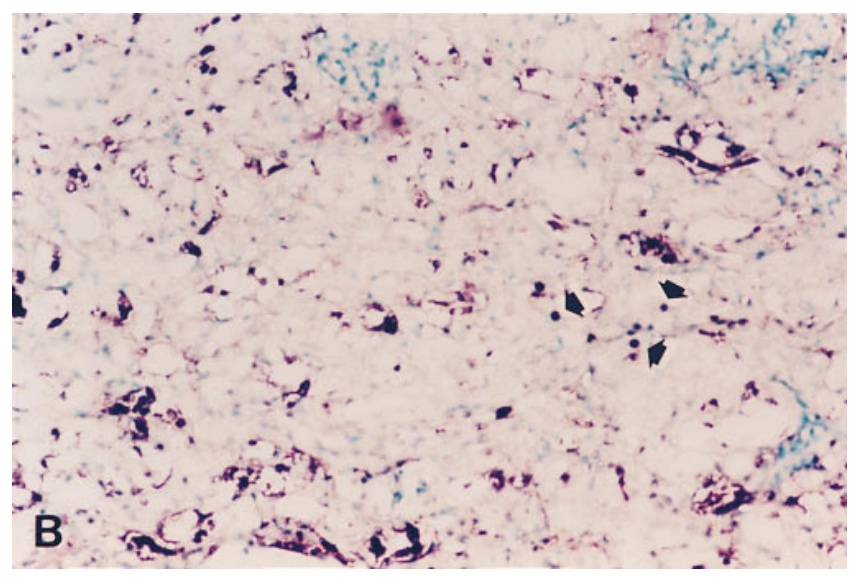

Figure 3. Appearance of apoptotic nuclei in kidney after cisplatin injection. TUNEL staining in kidney nuclei $3 \mathrm{~d}$ after injection in wild-type $(A)$ and $p 21(-/-)$ mice $(B) . \times 390$. Arrows indicate representative nuclei scored as "positive" for apoptosis. Quantitative evaluations of the number of apoptotic nuclei $(C)$ were based on at least five mice from each time point and genotype. Values represent means ( \pm standard error) of apoptotic nuclei observed per square millimeter section of kidney prepared from each genotype. $P$ values are indicated.

shown that p53-dependent apoptosis could occur in the absence of p21 induction (33), and that the induction of apoptosis in quiescent fibroblasts by c-myc was dependent on p53 induction (34), but not on p21 (35). Also, the p53-dependent apoptosis observed in $\gamma$-irradiated thymocytes was independent of the presence of a functional p21 gene (20). Recently, elevated p21 expression has been associated with cell survival rather than cell death or apoptosis $(36,37)$. The expression of $\mathrm{p} 21$ during differentiation had been found to block apoptosis of myoblasts under conditions of mitogen deprivation (38) and of SH-SY5Y neuroblastoma cells exposed to nerve growth factor and aphidicolin (39). Similarly, p21 overexpression protects both MCF-7 (40) and RKO cells (41) from prostaglandin $\mathrm{A}_{2}$ mediated apoptosis. We had shown that cisplatin injection caused p53 induction and p53-dependent p21 induction in murine kidney (1). We now show that the absence of p21 contributes to the appearance of much higher amounts of apoptotic cells in the kidney than would be observed with a functional p21 gene. Many types of acute renal failure have been associated with increased apoptosis of kidney cells $(42,43)$, although we have not detected p53 activation in renal failure caused by agents other than cisplatin (1). Therefore, it is possible that the increased apoptosis seen in $p 21(-/-)$ mice after cisplatin injection is caused by p53-dependent pathways, similar to those discussed above, and would not be seen after renal failure caused by, for example, ischemia or ureteral obstruction. 

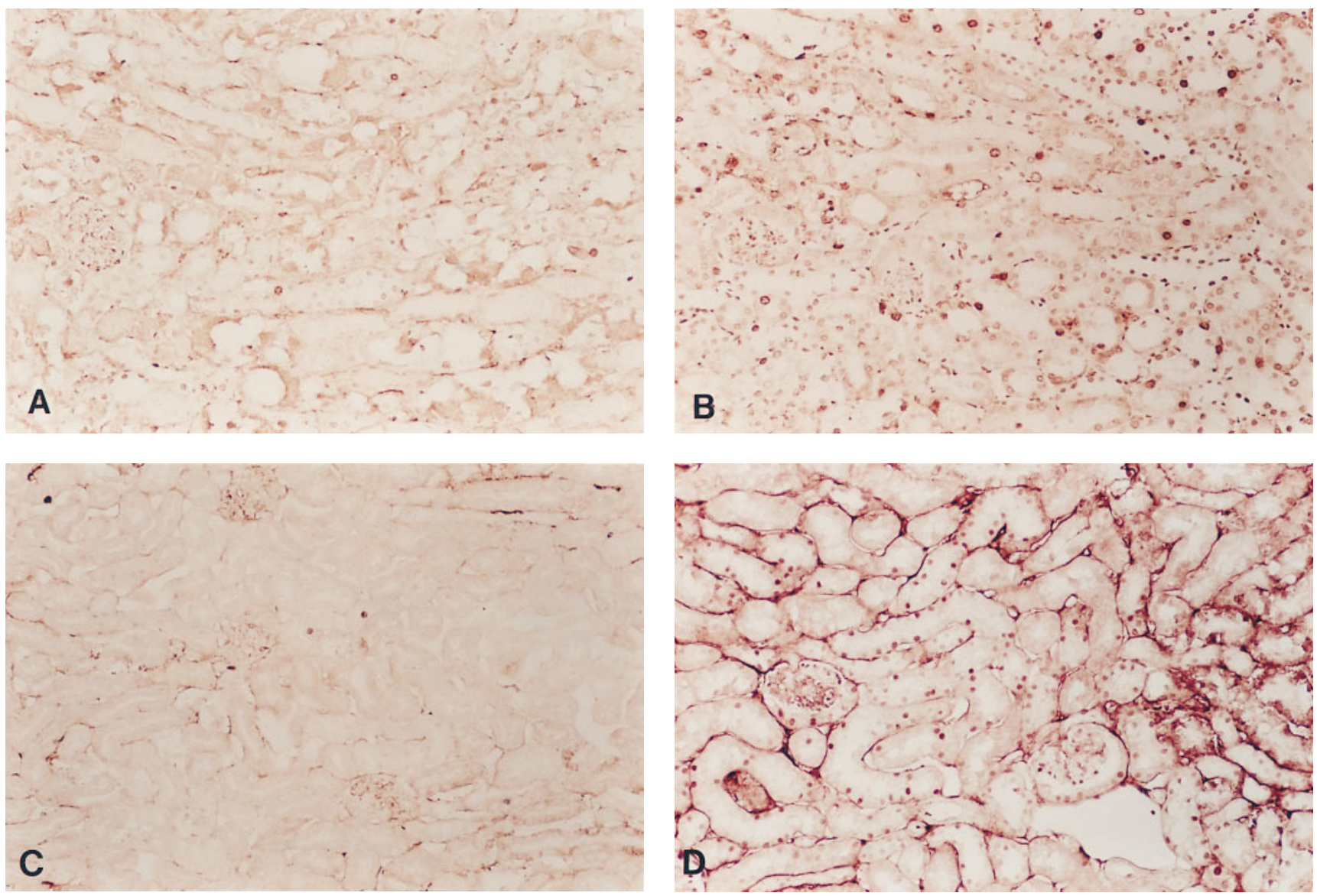

Figure 4. Cell-cycle analysis of kidney after cisplatin injection. Immunodetection of nuclear BrdU incorporation $4 \mathrm{~d}(A$ and $B)$ and of nuclear PCNA localization $1 \mathrm{~d}(C$ and $D)$ after injection. Sections were from wild-type $(A$ and $C)$ and $p 21(-/-)$ mice $(B$ and $D)$. $\times 390$.

Acute renal failure induced by many agents results in DNA synthesis by damaged tubule cells $(32,44)$, presumably a reparative event. Cisplatin injection resulted in increased amounts of the cell-cycle indicators BrdU incorporation and nuclear PCNA in kidney cells of both wild-type and $p 21(-/-)$ mice. However, the relative amounts of these indicators in the p21(-/-) population were much higher than those in the wildtype mice. The differences observed are likely a direct effect of

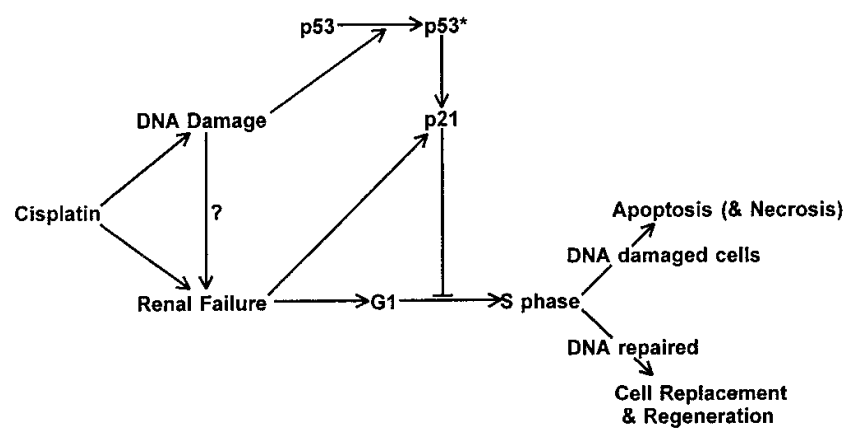

Figure 5. Proposed mechanism for the relationship between $\mathrm{p} 21$ overexpression in kidney and its cytoprotection after cisplatin injection. the lack of p21 expression in the "null" group, and they are also likely to be indicative of the mechanism underlying the apparent protective effect of the $\mathrm{p} 21$ protein. We propose that the following mechanism occurs in the kidney after cisplatin injection (Fig. 5). Cisplatin is a drug that causes both DNA damage (45) and nephrotoxicity. After cisplatin treatment, it is possible that these are interrelated, although many other agents that cause renal failure do not cause DNA damage. The damaged DNA is responsible for p53 activation (46, 47), which in turn induces p21 (2). We have shown that in kidney cisplatin injection causes p53 activation and both p53-dependent and p53-independent induction of the $p 21$ gene (1). We have also reported that other agents causing acute renal failure can induce p21 in the absence of p53 activation (1). The damaged cells attempt to regenerate and enter the cell-cycle (reference 44 and Fig. 4). In the presence of the cdk inhibitor, p21, most of the cells are prevented from progressing into S-phase until their DNA can be repaired, at which time they complete the replacement and regeneration cycle. However, in mice that are homozygous for a $p 21$ gene deletion, many kidney cells enter S-phase with damaged DNA, with subsequent cell death through necrosis (Fig. 2) and apoptosis (Fig. 3).

From these experiments, we cannot determine whether p21 has a role in the initiation of acute renal failure, although the lack of p21 induction contributes to an increased severity of 
both morphologic and functional kidney damage. Upregulation of p21 may be a therapeutic target to ameliorate cisplatininduced renal failure.

\section{Acknowledgments}

We thank Dr. Philip Leder (Harvard Medical School) for providing several heterozygous mice carrying the $p 21$ gene deletion, and for providing a probe for screening.

This work was supported, in part, by the University of Texas Medical Branch Small Grants Program.

\section{References}

1. Megyesi, J., N. Udvarhelyi, R.L. Safirstein, and P.M. Price. 1996. The p53-independent activation of transcription of $\mathrm{p} 21^{\mathrm{WAF} 1 / \mathrm{CIP} / \mathrm{SD} 11}$ after acute renal failure. Am. J. Physiol. 271:F1211-F1216.

2. El-Deiry, W.S., T. Tokino, V.E. Velculescu, D.B. Levy, R. Parsons, J.M. Trent, D. Lin, W.E. Mercer, K.W. Kinzler, and B. Vogelstein. 1993. WAF-1, a potential mediator of $\mathrm{p} 53$ tumor suppression. Cell. 75:817-825.

3. Harper, J.W., G.R. Adami, N. Wei, K. Keyomarsi, and S.J. Elledge. 1993. The p21 cdk-interacting protein Cip1 is a potent inhibitor of G1 cyclin-dependent kinases. Cell. 75:805-816.

4. Noda, A.F., Y. Ning, S. Venable, O.M. Pereira-Smith, and J.R. Smith. 1994. Cloning of senescent cell-derived inhibitors of DNA synthesis using an expression screen. Exp. Cell Res. 211:90-98.

5. Xiong, Y., H. Zhang, and D. Beach. 1992. D type cyclins associate with multiple protein kinases and the DNA replication and repair factor PCNA. Cell. 71:505-514.

6. Polyak, K., J. Kato, M.J. Solomon, C.J. Sherr, J. Massague, J.M. Roberts, and A. Koff. 1994. p27 $7^{\text {Kip1 }}$, a cyclin-Cdk inhibitor, links transforming growth factor-B and contact inhibition to cell cycle arrest. Genes Dev. 8:9-22.

7. Lee, M.-H., I. Reynisdóttir, and J. Massagué. 1995. Cloning of p57KIP2 a cyclin-dependent kinase inhibitor with unique domain structure and tissue distribution. Genes Dev. 9:639-649.

8. Matsuoka, S. M.C. Edwards, C. Bai, S. Parker, P. Zhang, A. Baldini, J.W. Harper, and S.J. Elledge. 1995. p57 $57^{K I P 2}$, a structurally distinct member of the p $21^{C I P I}$ Cdk inhibitor family, is a candidate tumor suppressor gene. Genes Dev. 9:650-662.

9. Li, Y., C.W. Jenkins, M.A. Nichols, and Y. Xiong. 1994. Cell cycle expression and p53 regulation of the cyclin-dependent kinase inhibitor p21. Oncogene. 9:2261-2268.

10. Zhang, H., G.J. Hannon, and D. Beach. 1994. p21-containing cyclin kinases exist in both active and inactive states. Genes Dev. 8:1750-1758.

11. LaBaer, J., M.D. Garrett, L.F. Stevenson, J.M. Slingerland, C. Sandhu, H.S. Chou, A. Fattaey, and E. Harlow. 1997. New functional activities for the p21 family of CDK inhibitors. Genes Dev. 11:847-862.

12. Halevy, O., B.G. Novitch, D.B. Spicer, S.X. Skapek, J. Rhee, G.J. Hannon, D. Beach, and A.B. Lassar. 1995. Correlation of terminal cell cycle arrest of skeletal muscle with induction of p21 by myoD. Science. 267:1018-1021.

13. Macleod, K.F., N. Sherry, G. Hannon, D. Beach, T. Tokino, K. Kinzler, B. Vogelstein, and T. Jacks. 1995. p53-Dependent and independent expression of p21 during cell growth, differentiation, and DNA damage. Genes Dev. 9:935944.

14. Parker, S.B., G. Eichele, P. Zhang, A. Rawls, A.T. Sands, A. Bradley, E.N. Olson, J.W. Harper, and S.J. Elledge. 1995. p53-Independent expression of $\mathrm{p} 21^{\mathrm{Cip} 1}$ in muscle and other terminally differentiating cells. Science. 267:10241027.

15. Skapek, S.X., J. Rhee, D.B. Spicer, and A.B. Lassar. 1995. Inhibition of myogenic differentiation in proliferating myoblasts by cyclin D1-dependent kinase. Science. 267:1022-1024.

16. Steinman, R.A., B. Hoffman, A. Iro, C. Guillouf, D.A. Liebermann, and M.E. el-Houseini. 1994. Induction of p21 (WAF-1/CIP1) during differentiation. Oncogene 9:3389-3396.

17. Zhang, W., L. Grasso, C.D. McClain, A.M. Gambel, Y. Cha, S. Travali, A.B. Deisseroth, and W.E. Mercer. 1995. p53-independent induction of WAF1/ CIP1 in human leukemia cells is correlated with growth arrest accompanying monocyte/macrophage differentiation. Cancer Res. 55:668-674.

18. Jiang, H., J. Lin, Z.Z. Su, F.R. Collart, E. Huberman, and P.B. Fisher. 1994. Induction of differentiation in human promyelocytic HL-60 leukemia cells activates p21, WAF1/CIP1, expression in the absence of p53. Oncogene. 9: 3397-3406.

19. Brugarolas, J., C. Chandrasekaran, J.I. Gordon, D. Beach, T. Jacks, and G.J. Hannon. 1995. Radiation-induced cell cycle arrest compromised by p 21 deficiency. Nature. 377:552-557.

20. Deng, C., P. Zhang, J.W. Harper, S.J. Elledge, and P. Leder. 1995. Mice lacking p21 CIPI/WAFI undergo normal development, but are defective in G1 checkpoint control. Cell. 82:675-684

21. Waldman, T., K.W. Kinzler, and B. Vogelstein. 1995. p21 is necessary for the p53-mediated G1 arrest in human cancer cells. Cancer Res. 55:51875190

22. Dulic, V., W.K. Kaufmann, S.J. Wilson, T.D. Tlsty, E. Lees, J.W Harper, S.J. Elledge, and S.I. Reed. 1994. p53-dependent inhibition of cyclindependent kinase activities in human fibroblasts during radiation-induced G1 arrest. Cell. 76:1013-1023.

23. El-Deiry, W.S., J.W. Harper, P.M. O'Conner, V.E. Velculescu, C.E. Canman, J. Jackman, J.A. Pietenpol, M. Burrell, D.E. Hill, Y. Wang, et al. 1994. WAF1/CIP1 is induced in p53-mediated G1 arrest and apoptosis. Cancer Res. 54:1169-1174

24. Gu, Y., C.W. Turck, and D.O. Morgan. 1993. Inhibition of cdk2 activity in vivo by an associated 20K regulatory subunit. Nature. 366:707-710.

25. Xiong, Y., G.J. Hannon, H. Zhang, D. Casso, R. Kobayashi, and D. Beach. 1993. p21 is a universal inhibitor of cyclin kinases. Nature. 366:701-704.

26. Xiong, Y., H. Zhang, and D. Beach. 1993. Subunit rearrangement of the cyclin-dependent kinases is associated with cellular transformation. Genes Dev. 7:1572-1583.

27. Flores-Rozas, H., Z. Kelman, F.B. Dean, Z.-Q. Pan, J.W. Harper, S.J. Elledge, M. O'Donnell, and J. Hurwitz. 1994. Cdk-interacting protein 1 directly binds with proliferating cell nuclear antigen and inhibits DNA replication catalyzed by the DNA polymerase delta holoenzyme. Proc. Natl. Acad. Sci. USA. 91:8655-8659.

28. Waga, S., G.J. Hannon, D. Beach, and B. Stillman. 1994. The p21 inhibitor of cyclin-dependent kinases controls DNA replication by interaction with PCNA. Nature. 369:574-578.

29. Li, R. S. Waga, G.J. Hannon, D. Beach, and B. Stillman. 1994. Differential effects by the p21 CDK inhibitor on PCNA-dependent DNA replication and repair. Nature. 371:534-537.

30. Gavrieli, Y., Y. Sherman, and S.A. Ben-Sasson. 1992. Identification of programmed cell death in situ via specific labeling of nuclear DNA fragmentation. J. Cell Biol. 119:493-501.

31. Godley, L.A., J.B. Kopp, M. Eckhaus, J.J. Paglino, J. Owens, and H.E. Varmus. 1996. Wild-type $p 53$ transgenic mice exhibit altered differentiation of the ureteric bud and possess small kidneys. Genes Dev. 10:836-850.

32. Megyesi, J., J. DiMari, N. Udvarhelyi, P.M. Price, and R. Safirstein. 1995. DNA synthesis is dissociated from the immediate-early gene response in the post-ischemic kidney. Kidney Int. 48:1451-1458.

33. Caelles, C., A. Helmberg, and M. Karin. 1994. p53-Dependent apoptosis in the absence of transcriptional activation of p53-target genes. Nature. 370: 220-223.

34. Hermeking, H., and D. Eick. 1994. Mediation of c-myc-induced apoptosis by $\mathrm{p} 53$. Science. 265:2091-2093.

35. Wagner, A.J., J.M. Kokontis, and N. Hay. 1994. Myc-mediated apoptosis requires wild-type p53 in a manner independent of cell cycle arrest and the ability of p53 to induce p21 $1^{\text {wafl/cipl }}$. Genes Dev. 8:2817-2830.

36. Canman, C.E., T.M. Gilmer, S.B. Coutts, and M.B. Kastan. 1995 Growth factor modulation of p53-mediated growth arrest versus apoptosis. Genes Dev. 9:600-611.

37. Polyak, K., T. Waldman, T.-C. He, K.W. Kinzler, and B. Vogelstein 1996. Genetic determinants of p53-induced apoptosis and growth arrest. Genes Dev. 10:1945-1952.

38. Wang, J., and K. Walsh. 1996. Resistance to apoptosis conferred by cdk inhibitors during myocyte differentiation. Science. 273:359-361.

39. Poluha, W., D.K. Poluha, B. Chang, N.E. Crosbie, C.M. Schonhoff, D.L. Kilpatrick, and A.H. Ross. 1996. The cyclin-dependent kinase inhibitor p21 WAFI is required for survival of differentiating neuroblastoma cells. Mol. Cell. Biol. 16:1335-1341

40. Gorospe, M., and N.J. Holbrook. 1996. Role of p21 in prostaglandin $\mathrm{A}_{2-}$ mediated cellular arrest and death. Cancer Res. 56:457-479.

41. Gorospe, M., X. Wang, K.Z. Guyton, and N.J. Holbrook. 1996. Protective role of $\mathrm{p} 21^{\text {Wafl/Cipl }}$ against prostaglandin $\mathrm{A}_{2}$-mediated apoptosis of human colorectal carcinoma cells. Mol. Cell. Biol. 16:6654-6660.

42. Kennedy, W.A., II, A. Stenberg, G. Lackgren, T.W. Hensle, and IS. Sawczuk. 1994. Renal tubular apoptosis after partial ureteral obstruction. $J$. Urol. 152:658-664.

43. Schumer, M., M.C. Colombel, I.S. Sawczuk, G. Gobe, J. Connor, K.M. O’Toole, C.A. Olsson, G.J. Wise, and R. Buttyan. 1992. Morphologic, biochemical, and molecular evidence of apoptosis during the reperfusion phase after brief periods of renal ischemia. Am. J. Pathol. 140:831-838.

44. Megyesi, J., J. DiMari, P. Price, and R. Safirstein. 1996. Renal cell fate following cisplatin (CP)-induced acute renal failure. J. Am. Soc. Nephrol. 7: 1842. (Abstr.)

45. Zamble, D.B., and S.J. Lippard. 1995. Cisplatin and DNA repair in cancer chemotherapy. Trends Biol. Sci. 20:435-439.

46. Kastan, M.B., O. Onyekwere, D. Sidransky, B. Vogelstein, and R.W. Craig. 1991. Participation of 533 protein in the cellular response to DNA damage. Cancer Res. 51:6304-6311.

47. Levine, A.J., J. Momand, and C.A. Finlay. 1991. The p53 tumor suppressor gene. Nature. 351:453-456. 